\title{
Rockburst support in shallow-dipping tabular stopes at great depth
}

\author{
D.F. Malan, J.A.L. Napier \\ Department of Mining Engineering, University of Pretoria, South Africa
}

\section{ABSTRACT}

This paper investigates the unique problems associated with the design of rockburst support for shallow-dipping tabular excavations. These designs are particularly problematic when the stoping width is very small. In steep dipping orebodies, the layouts and mining methods can be selected to ensure that miners never enter the stopes. Only the access drives need to be protected by rockburst resistant support. In shallow-dipping orebodies, this problem is more difficult as miners enter the stopes and the entire hanging wall needs to be supported. A simple analytical model is used to investigate the implications for support design as a result of the convergence associated with the tabular geometry and the possibility of rocks being ejected during a rockburst. This illustrates that a support system is required that is initially stiff, but it should also be yieldable to survive the convergence in the back areas. By trial and error, the historic support solutions in the South African gold mines evolved into a system of timber packs and elongates to meet these requirements. When considering the three accepted key functions of modern rockburst support methodology namely, reinforce, retain and hold, the typical support design for these shallow-dipping orebodies does not meet all these requirements. The rock is highly fractured and fallouts occur between roofbolts during rockbursts as areal support is difficult to implement. Steel mesh is not used as it is often destroyed during cleaning operations. Solving this problem is of critical importance to ensure the viability of deep South African gold mines in future.

Keywords: Rockburst support, Tabular stope, Areal support, Energy absorbing support;

\section{Introduction}

The rockburst problem in the deep gold mines in South Africa has been studied by many researchers ${ }^{1-8}$. Various measures to mitigate the risk to miners have been implemented over the last few decades and this appears to have been largely successful when examining the decrease in rockburst fatalities in South African mines from 2003 to $2016^{9}$. Unfortunately, a number of recent seismic disasters at various mines in 2017 and 2018 have resulted in a 
significant loss of life. Major disasters occurred at mines near Carletonville in South Africa on 25 August 2017, which resulted in 5 rockburst fatalities, and on 3 May 2018, which resulted in 7 rockburst fatalities. An in-depth investigation of various aspects of the mining process is urgently required to ensure safe and sustainable mining. This paper focusses on the general aspects of support in rockburst conditions and does not focus on the specific disasters at the two mines mentioned above.

In the South African mines, rockburst mitigation strategies can be broadly classified into two groups. Firstly, there are measures to reduce the number of damaging seismic events occurring during shift time. These include centralised blasting systems, layouts which minimise stress concentrations, the use of bracket pillars to prevent slip on geological structures and preconditioning. Secondly, measures are implemented to protect the miners in the stopes when a rockburst occurs during shift time. This involves the installation of rockburst resistant support with energy absorbing capabilities.

This paper will focus only on the second aspect and specifically on the historic development of panel support for the deep tabular stopes in South Africa. The paper seeks to identify aspects of stope support that require further research and development and does not consider tunnel support design. For tunnel support in rockburst conditions, readers can refer to publications such as Wagner6, Kaiser et al. ${ }^{10}$, Ryder and Jager ${ }^{11}$, Kaiser and Cai ${ }^{12}$ and Cai13.

\section{Support problems associated with a shallow dipping tabular orebody at great depth}

The Witwatersrand Basin is the greatest gold deposit to be discovered in history and to date more than 50000 tons of gold has been mined from this basin ${ }^{14}$. After more than 100 years of mining, most of the remaining orebody is located at great depth $(3-4 \mathrm{~km}$ depths in some mines). The associated rockbursts and the difficulty of providing adequate ventilation are two of the key engineering challenges when mining at these great depths.

A particularly difficult problem is the implementation of effective rockburst support with appropriate areal coverage. As illustrated in this paper, this problem is caused by the shallow dipping nature of the tabular orebody (Fig. 1). The average dip of the reef is $25^{\circ}$ to $35^{\circ}$ and the stoping width can be as low as $1 \mathrm{~m}$. As the dip is below the angle of repose of the broken ore, blasted reef needs to be cleaned using manual labour with scraper and winch arrangements and miners need to enter the hazardous stope face areas. To protect these miners, the systematic installation of on-reef support in the face area is required. Huge areas of hanging 
wall therefore need to be supported. This is particularly problematic in areas where the stoping width is very small.

It is useful to compare the shallow dipping orebodies of the South African gold mining industry to steeply dipping vein deposits in which mechanised mining methods such as sublevel open stoping or shrinkage stoping can be adopted ${ }^{15}$. For these mining methods, the dip must be steep enough to exceed the angle of repose of the broken rock. The advantage of these mining methods is that miners do not need to enter the stoped areas. If rockbursts are encountered in these mines, the problem is simplified as only the access drifts and loading crosscuts need to be adequately supported. In deep level South African gold mines, the angle of repose for broken ore is larger than the typical reef plane dip of $25^{\circ}$ to $35^{\circ}$ and the mined rock therefore needs to be removed with manual labour and equipment that can be accommodated within the small stoping width.

As early as 1924, the "Rock Burst Committee" appointed by the South African Government recognised "rock pressure" as one of the key problems facing mining engineers and made comments about the density of support required ${ }^{16}$. They mentioned that "Such authorities hold that, whereas, at 1200 to $1500 \mathrm{~m}$, a ratio of 35 per cent support compared to the area excavated has been found adequate, as working depths increase the necessary ratio of support may also increase; so that at a depth of $2400 \mathrm{~m}, 70$ per cent support may be necessary, and at $3000 \mathrm{~m}$ (if mining operations can be continued to that depth) 80 percent or more." Ironically, it seems as if areal support for rockburst conditions was already advocated in the early years of mining.

In summary, the shallow dipping nature of the deep orebodies in the South African gold mines presents a unique rock engineering support problem with the following attributes: Owing to the high extraction ratio and the need for miners to enter the on-reef stopes, a very large area needs to be supported. This needs to be done in a cost effective manner. The occurrence of seismic events requires that the support system be rockburst resistant with the capacity to prevent the total collapse of the stope. The highly fractured nature of the hanging wall, caused by the elevated stress levels at the mining face necessitates the use of areal support to prevent fallouts between support units. The stoping width, $\mathrm{h}_{0}$, may be as small as $1 \mathrm{~m}$ to 1.6 $\mathrm{m}$ to make the mining operation economically feasible. This affects the proper installation of roofbolts and the length of roofbolts that can be selected. The cleaning operations in such a small stoping width also affect areal support systems as the scraper and winch systems may pull out steel mesh support that is installed on the stope hanging wall.

There are a number of reasons why the support units need to remain effective in the back areas of the stopes. The miners gain access to the working faces through a system of on-reef 
gullies that are excavated as trenches in the immediate footwall of the stopes. These gullies form the only access routes to the working faces and traverse the back areas of the stopes. The support in the gullies and in the old stopes immediately adjacent to the gullies must remain effective to protect all personnel travelling in these excavations. In some stopes, significant convergence can occur in close proximity to the stope face. (Jager and Ryder ${ }^{11}$ give an example of $250 \mathrm{~mm}$ of convergence at a distance as close as $15 \mathrm{~m}$ from the stope face.) It should be noted that the only support type that has the capacity to minimise stope convergence at these great depths is backfill and this has the beneficial effect of reducing the energy release rate and associated seismicity ${ }^{11}$. Backfill is not used in all mines, however, owing to the complexity of the backfill plant and the piping infrastructure that is required to transport the fill over extensive vertical and lateral distances to the working stopes.

A successful rock engineering solution will require a support system that addresses the key issues described above. In spite of many decades of research, it remains a challenging problem. The conditions imposed by the geometry (shallow dipping tabular, small stoping width) is clearly a major hurdle. A number of partial solutions have been developed in the mining industry over many decades and an overview of these are given in the next section.

To provide further insight, consider the following simplified problem with the relevant geometric dimensions displayed in Fig. 1. Assume a parallel-sided tabular excavation that dips at an angle $\alpha$, which is smaller than the angle of repose of broken reef material. The dimension in the dip direction $y$ is very large compared to the half span $\ell$ of the stope in the strike direction $x$. The original stoping width or mining height, $\mathrm{h}_{0}$, is small compared to $\ell$ and it is assumed

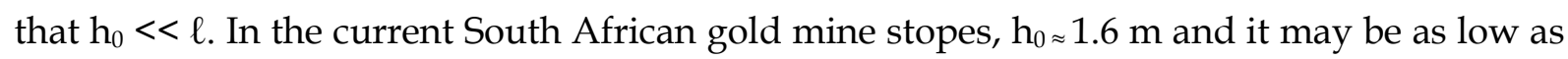
$1 \mathrm{~m}$. In modern dip pillar layouts, a typical value of the span is $2 \ell=200 \mathrm{~m}$. These spans were even larger in older longwall layouts. The stope is subjected to rockbursts and slabs of rock of a weight $\mathrm{M}_{\mathrm{b}}$ can be ejected from the hanging wall with a typical fallout height of $\mathrm{b} \approx 1 \mathrm{~m}$. The stope is supported by yielding elongate support units, which allow a maximum deformation, $\mathrm{d}_{\mathrm{m}}$, before failure of these units occurs. Except for the rock slabs in the immediate hanging wall, the rock mass is assumed elastic in nature. The rock slabs remain in position and will be subjected to the overall elastic deformation of the rock mass until ejected in a rockburst.

The excavation height, $h(x)$, below the slab of rock shown in Fig. 1 is dependent on the position in the stope and the effect of a possible rockburst and can be written as:

$$
h(x)=h_{0}-[S(x)+d] \geq 0,
$$

where $h_{0}$ is the original mining height, $\mathrm{S}(\mathrm{x})$ is the elastic convergence in the stope and $\mathrm{d}$ is the distance the rock slab is ejected during a rockburst. The support unit can only undergo a 
maximum deformation, $\mathrm{d}_{\mathrm{m}}$, before failure and a further condition that must be applied to ensure effective support of the excavation is:

$$
S(x)+d<d_{m}
$$

Eq. (2) applies an onerous restriction on the design of support units as the term $S(x)$ increases away from the face of the stope into the back area (shown below) and it reduces the deformation, $\mathrm{d}$, that the support system can resist during rockbursts. A number of studies have indicated that $S(x)$ is not only a function of the distance to the face, but is also timedependent owing to creep-like processes in the rock mass ${ }^{17-20}$. This aggravates the restrictive condition imposed by Eq. (2) on support system design as slow mining rates can result in failure of support units close to the stope face. These time-dependent deformations are not explored further in the current paper. The rock mass is assumed to be elastic to illustrate the typical problems associated with the support of shallow dipping tabular excavations.

The mining height, $h_{0}$, which is typically in the range of $1 \mathrm{~m}$ to $1.6 \mathrm{~m}$, imposes practical constraints on support selection. It is not feasible, for example, to drill long holes in the hanging wall to install $3 \mathrm{~m}$ roof bolts in the confined working space. Coupled drill rods can be used to achieve the required hole depth, but a single $3 \mathrm{~m}$ rigid bolt cannot be installed normal to the plane of the reef. For the geometry shown in Fig. 1, the maximum rigid bolt length, $L_{b}$, that can be used for installation is $L_{b}<h_{0}-S(x)$. The use of longer flexible cable anchors is a possibility, but drilling the deep holes by hand and grouting the anchors is not practical in the confined stoping height within the time constraints of the production cycle. The typical bolt length currently used in the gold mining industry on the reef horizon is $0.9 \mathrm{~m}$ and the key function of these short bolts is to prevent small ground falls between pack or elongate support.

In the following discussion it is assumed that the $S(x)$ component in Eqs. (1) and (2) corresponds to the elastic convergence $S_{Z}(x)$ in the direction $z$ normal to the reef plane (see Fig. 1). If it is assumed that the excavation is a parallel-sided panel at great depth and that no contact occurs between the hanging wall and the footwall, for the geometric orientation depicted in Fig. 1, Salamon ${ }^{21}$ has shown that for an isotropic, elastic host rock

$$
S_{z}(x)=\frac{-4\left(1-v^{2}\right) W_{z}}{E} \sqrt{\ell^{2}-x^{2}},
$$

where $W_{Z}$ is given by

$$
W_{z}=\frac{-\rho g H}{2}[(1+k)+(1-k) \cos 2 \alpha]
$$


In Eqs. (3) and (4), $2 \ell$ is the span of the stope, $\rho$ is the density of the rock, $g$ is the gravitational acceleration, $\mathrm{H}$ is the depth below surface, $\mathrm{k}$ is the ratio of horizontal to vertical stress, $\alpha$ is the dip of the reef, $v$ is Poisson's ratio and E is Young's modulus. The ride component $S_{y}(x)$ is proportional to $S_{z}(x)$ and is given by

$$
\frac{S_{y}(x)}{S_{z}(x)}=\frac{(1-k) \sin 2 \alpha}{(1-v)[1+k+(1-k) \cos 2 \alpha]}
$$

The ride component is zero if $k=1$ or if the reef dip, $\alpha=0$. When the reef dip is zero, $W_{Z}=-\rho g H$ and Eq. (3) can be simplified to

$$
S_{z}(x)=\frac{4\left(1-v^{2}\right) \rho g H}{E} \sqrt{\ell^{2}-x^{2}} .
$$

Substituting Eq. (6) into Eq. (2) yields the following inequality constraint that has to be met for support design:

$$
\frac{4\left(1-v^{2}\right) \rho g H}{E} \sqrt{\ell^{2}-x^{2}}+d<d_{m}
$$

Note that the constraint (7) assumes that the elongate support is installed right on the face where the convergence is zero and the distance between the support units and the mining face increases gradually as the mining span is incrementally increased. It is also assumed that the force exerted by the support units is not large enough to affect the elastic convergence $S_{Z}(x)$. The inequality constraint (7) will not be valid for support units installed at later stages in the back area of mature stopes or for very robust support, such as backfill, which can limit the elastic convergence occurring in the back areas.

Consider the case where a rockburst results in a dynamic deformation of $d=100 \mathrm{~mm}$. The other parameters assumed are $\ell=100 \mathrm{~m}, \mathrm{E}=70 \mathrm{GPa}, v=0.2, \rho=2700 \mathrm{~kg} / \mathrm{m}^{3}, \mathrm{~g}=9.81 \mathrm{~m} / \mathrm{s}^{2}$ and $\mathrm{H}=3500 \mathrm{~m}$. The support unit is assumed to be able to yield for a distance of $400 \mathrm{~mm}$ before failure, $d_{m}=400 \mathrm{~mm}$. The left hand side of (7) is plotted in Fig. 2, using these parameters, as a function of the distance $\ell-|x|$ from the stope face. This illustrates that at a distance of approximately $20 \mathrm{~m}$ from the face, the elastic convergence has already deformed the support unit to the extent that it will not be able to withstand a dynamic deformation of $100 \mathrm{~mm}$ caused by a rockburst. This example clearly illustrates the complication caused by the tabular excavations. The convergence experienced by the support units as they move into the back areas render them ineffective as rockburst support in these back areas as the yieldability of the units are diminished (see Fig. 3). 
During a rockburst, the velocity, $v$, at which the rock is ejected is important to estimate the magnitude of dynamic deformation, $d$. It is assumed that the mass of the support $M_{p}$ is much smaller than the mass of the block ejected $\mathrm{M}_{\mathrm{b}}$. The rock slab move downwards and is gradually brought to rest by the support resisting force $\mathrm{F}(\mathrm{z})$. Equating the changes in kinetic energy and potential energy to the work done by the resisting force gives the following equation:

$$
\frac{M_{b} v^{2}}{2}+M_{b} g d \cos (\alpha)=\int_{0}^{d} F(z) d z
$$

A similar analysis was carried out by Wagner6. The load-deformation behaviour, $\mathrm{F}(\mathrm{z})$, of the various support units vary greatly and these can be used to evaluate Eq. (8). One special case is the rapid yield hydraulic prop (RYHP) support units that was popular in the South African mining industry in the 1970s and 1980s. These props supplied a constant resisting force $F(z)=F_{c}$ during rockbursts. This assumption is also a good approximation for some of the modern yieldable steel elongates. By assuming the use of these props and if the dip is zero, Eq. (8) can be simplified to:

$$
\frac{M_{b} v^{2}}{2}+M_{b} g d=F_{c} d
$$

This can be written as:

$$
d=\frac{v^{2}}{2\left(\frac{F_{c}}{M_{b}}-g\right)}
$$

Note that a singularity is present in Eq. (10) if the ratio $\left(F_{c} / M_{b}\right)$ approaches the value of g. In practice, it is therefore important to install supports units with a specific load bearing capacity, $F_{c}$, at the correct spacing to ensure a large value for the ratio $\left(F_{c} / M_{b}\right)$. Eq. 10 is plotted in Fig. 4 to illustrate the effect of support force and ejection velocity on the deformation experienced in the stope. At the higher ejection velocities, a more robust support system is required to arrest the block movement within a specified distance. For a specific support system, the dynamic closure increases rapidly with the square of the ejection velocity (Fig. 5). Based on the earlier information given in Fig. 2, this implies that high ejection velocities will typically result in support failure in the back areas of the stope where significant elastic convergence has already taken place. 
Eq. (10) can be combined with (7) to give the general constraint condition for an elongate support with a constant deformation resistance force $F_{c}$ in rockburst conditions, based on the assumptions shown in Fig. 1:

$$
\frac{4\left(1-v^{2}\right) \rho g H}{E} \sqrt{\ell^{2}-x^{2}}+\frac{v^{2}}{2\left(\frac{F_{c}}{M_{b}}-g\right)}<d_{m}
$$

The constraint condition imposed by (11) will not be met if the support units have either already failed as a result of excessive convergence in the back area of the stope or if the velocity of ejection or mass is too large to be contained by the force supplied by the support unit during a rockburst.

It is of significance is that the constraint (11) illustrates that elongate support units may be effective during rockburst conditions installed in the face area, $(|x| \cong \ell)$, but not in the back area where the extent to which the support can yield has been diminished by the stope convergence. A similar principle for rockburst support design of tunnels was recently discussed by Cai and Kaiser22. The concept is referred to as "support capacity consumption" and is caused by the static and dynamic deformation of the rock mass. This consumes the energy absorption capacity of the tunnel support system and capacity restoration is recommended by implementing "Proactive Support Maintenance" (PSM). For this maintenance, new rock bolts are installed to provide additional displacement capacity. For tabular stope support, a different approach is adopted where different types of support units are used in combination. This mitigates the effect of support capacity consumption in the back areas, while still maintaining an adequate resisting force $\mathrm{F}(\mathrm{z})$ in the face area.

It is important to establish the ejection velocity, $v$, during rockbursts and the force, $F(z)$ exerted by the unit when selecting appropriate support units. The correct assessment of these factors make the selection of effective rockburst support in tabular stopes a difficult problem. It is not clear what ejection velocity should be used in support design, although the value of $3 \mathrm{~m} / \mathrm{s}$ has been adopted in the South African gold mining industry as a compromise. The mass of the ejected rock, $\mathrm{M}_{\mathrm{b}}$, is also typically based on prior experience of ejection thicknesses and may not be applicable in all cases.

It should be noted that the fatality statistics shown in Fig. 1 focus on the ejection of rock from the hanging wall. A risk that is not well understood is the occurrence of significant footwall heave during seismic events. Cases are known to have occurred where this type of deformation has led to fatal accidents that were caused by miners being thrown against the 
hanging wall. The energy absorption capacity of the support units is of little benefit if this type of unstable deformation occurs. The primary method that is used to mitigate this risk is the design of layouts which include clamping pillars on geological structures to prevent or minimise sudden slip on these structures. The role of the elongate and pack support in these cases will primarily be to prevent shakedown of loose blocks in the hanging wall.

It should also be emphasised that the constraint (11) is valid only if the force supplied by the support units does not affect the elastic convergence. A simple numerical modelling study of the effect of backfill was conducted using the boundary element code TEXAN ${ }^{23}$ to illustrate the effect of robust support, such as backfill, on convergence. A backfill model with a hyperbolic reaction stress is computed using the equation:

$$
R_{B}(\varepsilon)=\frac{a \varepsilon}{(b-\varepsilon)}
$$

where $a$ and $b$ are specified parameters for the fill material and $\varepsilon$ is the nominal strain computed from the relationship:

$$
\varepsilon=1-\frac{\left(h_{0}-S_{z}\right)}{h_{B}} .
$$

In Eq. (13), $h_{0}$ is the stope width, $h_{B}$ is the fill placement height and $S_{z}$ is the normal component of elastic convergence. In the TEXAN code, $\mathrm{h}_{\mathrm{B}}$, is computed using the value of the stope closure prior to the mining step when placement occurs and using a specified fill "gap" distance, $G_{n}$. The parameters are $a$ which is the hyperbolic fill material parameter (MPa), $b$ is the hyperbolic fill material maximum nominal strain fraction, $\mathrm{h}_{0}$ is the stope width $(\mathrm{m})$ and $G_{n}$ is the fill gap distance $(\mathrm{m})$.

A stope of span $200 \mathrm{~m}$ was simulated at a depth of $3500 \mathrm{~m}$. The other parameters assumed were $\mathrm{E}=70 \mathrm{GPa}, v=0.2, \rho=2700 \mathrm{~kg} / \mathrm{m}^{3}, a=6 \mathrm{MPa}$ and $b=0.4$. The values assigned to the backfill parameters $a$ and $b$ are typical for the actual classified tailings material used as backfill in South African gold mines ${ }^{11}$. The results are shown in Fig. 6, which illustrates that the convergence at the centre of the stope is significantly less if backfill is used in the stope. In cases where backfill is used and the spans are large, inequality (11) will therefore not be valid, especially at large distances from the stope face.

A problem with support, such as backfill and timber packs, is that these types of support only provide a substantial resistance force once a significant amount of convergence has occurred. For backfill, this is evident from the model described in Eqs. (12 and (13). If perfect placement of backfill is assumed, it follows that $h_{0}=h_{B}$ and from Eqs. (12) and (13) 


$$
R_{B}\left(S_{Z}\right)=\frac{a S_{z}}{\left(h_{0} b-S_{z}\right)}
$$

From Eq. (4), it is apparent that $S_{z}$ is small if $(|x| \cong \ell)$. From Eq. (14), the reaction stress of the backfill is therefore very small in the face area of the stope.

This example highlights the need for a support system which combines units with different attributes. In the face area, a pre-stressed support type with enough yield capacity and sufficient force to minimise the damage caused by rockbursts is required. Practical support units that can fulfil this requirement, typically fail in the back areas where the stope convergence is large. A robust back area support system is therefore also required. Both these types of support must be practical to ensure that they can be installed when the stoping width is small. Care should also be exercised that the requirements of the constraint (7) are fulfilled at the particular distance to face where one support type takes over from the other. This may, for example, be problematic with RYHP in the face area and backfill behind the props. The low force exerted by the backfill close to the face may allow for significant deformation of the hanging wall into the backfill. This may exacerbate possible unravelling of the hanging wall between the face and the backfill. The support systems in the South African gold mining industry described below illustrate some of the practical solutions that have emerged over time for the problems described here.

\section{The development of stope support in the South African mining industry}

As early as 1926, the compressibility of sand-filled pipes and telescopic sticks were tested underground at Crown Mines24. Reinforced concrete rings filled with sand were also tested underground. Professor Walker of the University of the Witwatersrand and some of the mine managers continued with this testing work. As many of experiments were not conducted under standardised conditions, Bowen ${ }^{24}$ embarked on an extensive testing programme of various types of support in the 1930s. He tested poles, concrete discs, chock mats, stone-filled packs, pigsties and sloan-wire packs. Findings such as: "There is a definite correlation between the diameter of the pole and maximum load." were recorded for the first time. His testing produced load-compression curves for the different types of support and this was the first step towards an engineering approach to the design of these support system.

Jeppe $^{16}$ gave a description of the types of support used in the mining industry in 1946. His description is useful as it indicates that many of the support types that are currently installed 
in stopes were already in use more than 70 years ago. A summary of his list of support types is given below:

Timber Sticks or Props: These were used for local support under bad sections of hangingwall, but were also installed systematically at the stope face. A typical spacing in those years were at $1.2 \mathrm{~m}$ to $2.1 \mathrm{~m}$ centres on dip and strike. Square headboards were used to prolong the life of the props. A compressible type of pipe support was also available (Fig. 7) which comprised a stick fitted into a pipe filled with sand.

Mat Packs or "Chocks": These packs were first introduced in the Nourse Mine close to Johannesburg during April 1928. Jeppe describes them as the most common type of support in the gold mines in his 1946 publication. These packs are still common in the industry in modern times. They are built in mats made of round, dressed (chocks) or square timber. The timbers are rotated by 90 degrees for successive layers to ensure a sturdy construction (Fig. 8). The timbers in the mats were held together wire rope, although the modern chock packs are built from chocks transported individually to the stope face. "Wedging" or pre-stressing of the packs was effected in the early years by driving timber wedges into the packs. Inflatable steel bladders or cement bags are currently used. The popularity of the timber packs is due to the fact that their load carrying capacity increases rapidly at large deformations and these packs will still function very well in the back areas. Mat packs are therefore well suited to meet the requirements of the constraint relationship (7) and Eq. (8) in areas where $|x| \ll \ell$. For timber packs, when considering constraint (7), it follows that $d_{m}=h_{0}$. Fig. 9 illustrates the deformation of packs in old back areas where total closure has occurred.

Pigsty: Pigsties were a type of pack constructed by building a framework ("crib") of round laggings. Waste rock was packed in the lagging frame and the pigsty itself was filled with neatly packed waste rock. Pigsties had the advantage that they could be built from mostly waste material that was easily available. It was nevertheless difficult to build them solidly.

Sandfilling: This was already used by 1946 and was essentially a form of backfill. Paddocks were constructed by erecting a barricade at the bottom and sides of the area to be filled (Fig. 10). Sand from the mine dumps were used and about 30 percent water added. This was fed through boreholes into the underground workings.

Some tests were conducted on the load-deformation behaviour of the support units in the early years ${ }^{16}$, but no information regarding the effectiveness of the different types to minimise rockburst damage was given in this early literature. The 1924 Rockburst Committee made the comment that in mining methods where remnants are eliminated, rigid support may be replaced by systematic pack compressible support or even by stick support. At that stage, the 
few experiments that were performed by mines using this approach were apparently successful. Prop support was tested at a depth of $1500 \mathrm{~m}$ in a longwall at Crown Mines in 1930 with apparent success. Hill25 subscribed to a theory proposed by Joseph who hypothesised that "prevention of the bending, bulging or sag of strata into the stoped-out area would stop rockbursts". Hill therefore wanted to use incompressible support and selected props (mine poles) based on the testing carried out by Bowen. In 1941, he conducted a prop support experiment in a longwall at East Rand Proprietary Mines at a depth of $2100 \mathrm{~m}$. The props were spaced $0.9 \mathrm{~m}$ to $1.2 \mathrm{~m}$ apart on strike and dip. As a safety measure, rows of matt packs were installed every $7.6 \mathrm{~m}$. Observations indicated that at $27 \mathrm{~m}$ from the face, all the props had failed and the packs took over (Fig. 11). This behaviour is in agreement with the simple analytical model given by the constraint (7). At a distance to face of $x>10 \mathrm{~m}$, the convergence exceeded the maximum deformation, $\mathrm{d}_{\mathrm{m}}$, of 60 percent of the elongates. The scatter in the results is caused by the variability of the timber strength and the localised loading conditions to which the props are subjected. It was concluded by Hill that the approach worked, although it is more likely that the significant reduction in rockbursts which he observed was related to the introduction of longwall mining configurations and not by the use of "rigid" sticks.

There was no consensus in 1946 regarding the role of compressible support in rockburst conditions. Jeppe noted that rigid supports are unsatisfactory in rockburst conditions as the support unit may either suddenly collapse or punch into the hangingwall or footwall. However, if the supports were too compressible, they allow too much convergence. Jeppe felt that the ideal support should slow down the convergence process until the particular stoping section had been abandoned. Jeppe stated: "The possibilities of methods of support, which allow the violent forces of a rockburst to expend themselves on weaker members of the support before they fall on the main members, have not as yet been fully explored." He was therefore already advocating for a support system with energy absorption capabilities consisting of a mixture of different types in those early years.

A major development in terms of stope support occurred in the late 1960's when the Chamber of Mines Research Organisation (COMRO) developed the first rapid yield hydraulic props (RYHP ${ }^{26}$. Investigations of rockburst damage led to the specification of a prop suitable for use in deep-level gold mines. The initial specifications required a yield load of $360 \mathrm{kN}$, a setting load of $180 \mathrm{kN}$ and a yield travel of at least $30 \mathrm{~cm}$. The yield rate had to be as rapid as $0.3 \mathrm{~m} / \mathrm{s}$ over a distance of $15 \mathrm{~cm}$. The length of the prop was specified to be $1.12 \mathrm{~m}$ when fully extended and $0.66 \mathrm{~m}$ when collapsed. Orders for props were placed with two companies namely Fletcher, Sutcliffe and Wild and Klöckner-Ferromatik S.A. (Pty) Ltd. These props 
essentially consisted of a cylinder tube and a piston with a yield valve. The prop is extended and pre-stressed using pressurised water. The valve controls the release of the water in rockburst conditions to maintain a constant yield load while the prop is deforming (Fig. 12).

COMRO built a special rapid compression test machine to test these props under rockburst conditions. For the initial underground trial, 300 props were installed underground at East Rand Proprietary Mines in the 66 West panel, K-longwall, during October 1968. According to Hodgson, the results from the initial trials indicated that that these props "dramatically reduced damage due to rockbursts and rockfalls." This was probably owing to the installation of a stiff support system in the face area compared to the adjacent panels which were supported using timber packs only. This can possibly be explained by the results in Fig. 4 where, in the face area, the RYHP provide a significantly larger $\left(F_{c} / M_{b}\right)$ ratio compared to timber packs. A further trial with a larger number of props were conducted in 1970 and 1971. An interesting aspect was that the RYHP assisted by reducing the stoping width. At the end of these trials, the specifications of the props were modified to include a yield rate of $1 \mathrm{~m} / \mathrm{s}$ and a yield travel of $0.45 \mathrm{~m}$ for the long prop ( $1.1 \mathrm{~m}$ extended) and $0.35 \mathrm{~m}$ for the short prop ( 0.9 m extended). Jager ${ }^{27}$ reported that 700000 RYHP were purchased by the mines over the years and 240000 were in use by 1992. Currently there are almost none of these RHYP in use mainly owing to the growth in the use of yieldable timber elongates in the industry ${ }^{28}$. Modern yieldable steel elongates are also used in high risk areas.

The original specification and the change in specification of the yield rate for the RYHP highlights an important aspect of rockburst design that is not yet resolved. During the early underground trials, a reported rockburst on 28 October 1970 resulted in the stope convergence exceeding $300 \mathrm{~mm}$ and six props were split open and others were damaged. By examining the damaged props, the researchers estimated a rate of closure of $6 \mathrm{~m} / \mathrm{s}$. Wagner ${ }^{6}$ provided a table of rockburst damage information from 6 large seismic events and the estimated peak velocities varied from $0.4 \mathrm{~m} / \mathrm{s}$ to $3.5 \mathrm{~m} / \mathrm{s}$. Jager ${ }^{27}$ summarised the findings of various researchers to estimate peak ground velocities. Based on these studies it was decided that the new generation of RYHP should have a yield rate capability of $3 \mathrm{~m} / \mathrm{s}$ ( $80 \%$ of damaging events will result in velocities less than $3 \mathrm{~m} / \mathrm{s}$ ). This value seems almost arbitrary as it is not based on actual measurements and it caters for only $80 \%$ of damaging events. Further work regarding this ejection velocity is required.

\section{The need for robust areal support systems in tabular stopes}


Kaiser and Cai12 emphasised the three key functions of rockburst support. These three functions can be designated by the following keywords: reinforce (strengthen and control bulking), retain (prevent fractured blocks falling between reinforcing elements) and hold (anchor reinforcing elements in stable ground). As stated by them: "Under high stress conditions, fractured rocks between reinforcing or holding elements may unravel if they are not properly retained." When relating this to the support methodology used in the stopes of the South African gold mines, it is clear that great emphasis was placed on the reinforce and holding aspects, but not so much on the retaining function. In Fig. 1, the assumption of each yielding elongate supporting a block of width $\mathrm{t}$ (Tributary Area Theory; Roberts ${ }^{29}$ ) dominated the support design methodology for many years. This approach is described in detail in Ryder and Jager11 where a graphical method is used to determine whether particular support units at a particular spacing meet the support resistance and energy absorption criteria at a specified distance from the face. The requirement of retaining some support capacity between the holding elements is not explicitly included in this design methodology. Jager and Ryder ${ }^{30}$ nevertheless stated: "The predominant cause of falls of ground in stopes is inadequate areal coverage or interaction between support units." A closer spacing of units will be beneficial, but the spacing in the strike direction is typically dictated by the need to scrape between rows of support with the scraperwinch equipment during cleaning operations. Examples of fallouts during rockbursts that are related to a lack of robust areal coverage are shown in Figs. 13 and 14.

Jager and Ryder ${ }^{30}$ noted that a basic measure of areal coverage is the percentage that the contact area makes of the total area of the hanging wall. For typical elongate systems this is $<1 \%$ and for pack systems this is $<10 \%$. Clearly this is a significant risk to miners during rockburst conditions in deep tabular stopes where the hanging wall is intensely fractured.

A number of measures, such as headboards, bolting between elongates and packs and temporary nets are currently implemented in the face area in an attempt to alleviate this problem. Installation of bolting is problematic in the small stoping widths and special rigs must be used for drilling the holes. The bolting length is limited to short lengths (typically 0.9 $\mathrm{m}$ ) owing to the small mining height. This is problematic if the fallout height $b$ (Fig. 1) is larger than the bolt length. Steel rope nets can be left permanently in place, but these are susceptible to damage by the scrapers in low stoping width environments. Although some success has been achieved with these measures, a more robust permanent areal support system is required for rockburst conditions.

Owing to the practical problems associated with installing and retaining support elements (areal support) in narrow stoping width tabular excavations, researchers focussed attention on 
quantifying stable spans between support units11,31. These investigations attempted to "engineer" the spacing of the elongate and pack support to compensate for the lack of areal support. These studies typically require a number of assumptions to be made such as friction angle, height of instability, horizontal clamping stress and dip of the fractures. It is therefore extremely difficult to apply this in practice with confidence. It is not considered practical to adopt this approach owing to the constantly varying conditions in the rock mass and the difficulty to measure clamping stress. To further illustrate this problem, consider the simplified support problem shown in Fig. 15.

Theoretically, the block with mass $\mathrm{M}_{\mathrm{b}}$ shown in the figure will be stable provided that the horizontal clamping stress $\mathrm{F}_{\mathrm{h}}$ is:

$$
F_{h} \geq \frac{M_{b} g}{2 \tan \phi}
$$

where $g$ is gravitational acceleration and $\phi$ is the friction angle.

The horizontal clamping force in an underground stope was measured by Squelch ${ }^{32}$ and found to be of the order of 1 to $10 \mathrm{MPa}$. The elastic solution of a simple tabular stope indicates that the hanging wall should be in tension, but it seems as if the dilation caused by the fracturing ahead of the stopes creates compression in these hangingwalls ${ }^{33}$. The exact figure of $F_{h}$ will unfortunately not be known in every stope. The effect of dynamic movements caused by rockbursts on this clamping stress is furthermore a complex problem. Additional difficulties are that the height of potential instability, $b$, and the friction angles are not known for all mining areas. Shallow dipping discontinuities will also cause instabilities. Based on these arguments, it is considered impractical to use theoretical calculations of hanging wall block stability to define support spacing, especially to cater for rockburst conditions. A sound engineering approach will have to involve the three components of rockburst support proposed by Kaiser and Cai12 namely reinforce, retain and hold. Future focus will have to be placed on using robust and cheap areal support systems, or alternatively change the mining method to remove the presence of miners in high risk areas.

Cai and Champaigne ${ }^{34}$ summarised the rockburst support design process to comprise seven principles. These are: 1) avoid the rockburst; 2) use yielding support; 3) address the weakest link; 4) use an integrated system; 5) simplicity; 6) cost effectiveness; 7) anticipate and be adaptable.

When considering these principles, the South African gold mining industry has made tremendous strides in terms of steps 1 and 2. However, step 3 in which the weakest link is areal support, has not been adequately addressed. This also leads to a weakness in the fourth 
step namely that there is inadequate integration been the methods for areal support and the individual yielding support units. Louchnikov and Sandy ${ }^{35}$ emphasised that "...the weakest link in a ground support system is often the surface support, including the connections with the rockbolts." A key objective of the present paper is to highlight this problem for the South African mines as an issue caused mainly by the geometric constraints of a small stoping width and a flat dipping tabular geometry. Based on this, it must be questioned whether it will ever be possible to design cost-effective rockburst support systems with good areal characteristics for these conditions?

A possible solution to this support problem is a change in mining method which will remove miners from the stope faces. One such method is the use of reef boring techniques where the reef is drilled out by boring machines from pre-developed access drives ${ }^{36}$. These access drives can then be well protected by rockburst resistant support with the appropriate areal coverage.

\section{Conclusions}

This paper investigates the unique problems associated with the design of rockburst support for shallow-dipping tabular excavations. These geometries are commonly encountered in the deep gold mines of South Africa. The support designs are particularly problematic when the stoping width is very small as there is a restriction on the length of roofbolts that can be installed. Support elements providing areal coverage, such as steel mesh, are typically damaged during the cleaning operations by the use of scrapers. In steep dipping orebodies, the layouts and mining methods can be selected to ensure that miners never enter the stopes. Only the access drives need to be protected by rockburst resistant support. In shallow-dipping orebodies, this problem is far more difficult as miners enter the stopes and the entire stope hanging wall needs to be supported.

A simple analytical model is presented in the paper to highlight the implications for support design of the ambient elastic rock convergence associated with a tabular mine geometry and the possibility of rocks being ejected during a rockburst. This illustrates that the support system should initially be stiff, but should also possess sufficient yielding capacity to function in the back areas. Through trial and error, the historic support solutions in the South African mining industry have evolved into a system of combining elongate support units and timber packs to meet these requirements. The rapid yielding hydraulic prop was a revolutionary development for the deep gold mines, but these props have now been mostly 
replaced with yieldable timber elongates and permanent steel elongates in high risk areas. Regarding rockburst support design, the velocity of hanging wall block ejection is still largely unknown in spite of the widely accepted nominal design value of $3 \mathrm{~m} / \mathrm{s}$. This aspect requires further investigation.

When considering the three accepted key functions of modern rockburst support methodology namely reinforce, retain and hold, the support design for shallow-dipping tabular orebodies does not meet all these requirements. The rock is typically highly fractured and fallouts occur between roofbolts during rockbursts. Areal support is difficult to implement owing to the small stoping width and permanent steel mesh is not used as this is often destroyed during the blasting and cleaning operations. Solving this problem is of critical importance to ensure the viability of deep South African gold mines in future. A possible solution is to remove miners from the hazardous stope faces and implement methods such as reef boring to extract the reef.

\section{References}

1. Mickel RE. Pressure Bursts. Papers and Discussions 1931 - 1936, Association of Mine Managers of the Transvaal. 1933:393-428.

2. Hill FG. A system of longwall stoping in a deep level mine with special reference to its bearing on the pressure burst and ventilation problems. Association of Mine Managers of the Transvaal. 1942;1:257-76.

3. Cook NGW, Hoek E, Pretorius JPG, Ortlepp WD, Salamon, MDG. Rock Mechanics Applied to the Study of Rockbursts. J. S. Afr. Inst. Min. Metall. 1966;66:435-528.

4. Heunis R. The development of rock-burst control strategies for South African gold mines. J. S. Afr. Inst. Min. Metall. 1980;80:139-50.

5. Ortlepp WD. Rockbursts in South African gold mines: a phenomelogical view. In: Proceedings of the First International Congress on Rockbursts and Seismicity in Mines 1982. p. $165-78$.

6. Wagner H. Support requirements for rockburst conditions. In: Proceedings of the First International Congress on Rockbursts and Seismicity in Mines 1982. p. 209-18.

7. Gay NC, Spencer D, Van Wyk JJ, Van der Heever PK. The control of geological and mining parameters on seismicity in the Klerksdorp goldmining district. In: Proceedings of the First International Congress on Rockbursts and Seismicity in Mines 1982. p. 107-20. 
8. Durrheim RJ. Mitigating the risk of rockbursts in the deep hard rock mines of South Africa: 100 years of research, In: Extracting the Science: a century of mining research. Phoenix; 2010. P. 156-71.

9. Malan D, Napier J. A limit equilibrium fracture zone model to investigate seismicity in coal mines. Int. J. Min. Sci. Technol. 2018. https://doi.org/10.1016/j.ijmst.2018.08.003

10. Kaiser PK, McCreath DR, Tannant DD. Canadian Rock Burst Support Handbook. Sudbury, Ontario: Canadian Mining Industry Research Organisation; 1996.

11. Ryder JA, Jager AJ. A textbook on rock mechanics for tabular hard rock mines. Johannesburg: SIMRAC; 2002.

12. Kaiser PK, Cai M. Design of rock support system under rockburst condition. J. Rock Mech. Geotech. Eng. 2012;4(3):215-27.

13. Cai M. Principles of rock support in burst-prone ground. Tunneling and Underground Space Technology. 2013;36:46-56.

14. Malan DF. Krugerrand - Golden Jubilee. Johannesburg: Prestige Bullion; 2016.

15. Atlas Copco Manual. Ljungforetagen AB, Orebro: Atlas Copco; 1982.

16. Jeppe CB. Gold Mining on the Witwatersrand Vol. 1. Johannesburg: The Transvaal Chamber of Mines; 1946.

17. Malan DF. A viscoelastic approach to the modelling of transient closure behaviour of tabular excavations after blasting. J. S. Afr. Inst. Min. Metall. 1995;95:211-20.

18. Malan DF. Time-dependent behaviour of deep level tabular excavations in hard rock. Rock Mech. Rock Engng. 1999;32(2):123-55.

19. Napier JAL, Malan DF. A viscoplastic discontinuum model of time-dependent fracture and seismicity effects in brittle rock. Int. J. Rock. Mech. Min. Sci. \& Geomech. Abstr. 1997;34:1075-89.

20. Malan DF, Napier JAL. Reassessing continuous stope closure data using a limit equilibrium displacement discontinuity model. J. S. Afr. Inst. Min. Metall. 2018;118:22733.

21. Salamon MDG. Two-dimensional treatment of problems arising from mining tabular deposits in isotropic or transversely isotropic ground. Int J Rock Mech Min Sci. 1968;5:159185.

22. Cai M, Kaiser PK. Rockburst Support Reference Book - Volume 1: Rockburst phenomenon and support characteristics. Unpublished limited distribution manuscript; 2018.

23. Napier JAL, Malan DF. The computational analysis of shallow depth tabular mining problems. J. S. Afr. Inst. Min. Metall. 2007;107:725-42. 
24. Bowen JW. The suitability of support used underground. Papers and Discussions 1931 1936, Association of Mine Managers of the Transvaal. 1940;421-40.

25. Hill FG. An experiment on support at depth at the East Rand Proprietary Mines, Ltd. Association of Mine Managers of the Transvaal. 1942;1:413-19.

26. Hodgson K, White AJA, Cook NGW, Muller SC. Rapid-yielding hydraulic props as stope support in deep gold mines. Chamber of Mines Research Organisation Report. Research Report No. 25/72. 1972.

27. Jager AJ. Two new support units for the control of rockburst damage, In: Rock Support in Mining and Underground Construction, Proceedings of the International Symposium on Rock Support. Sudbury; 1992. p. 621-31.

28. Roberts MKC. An evaluation of yielding timber props as a support system in rockburst conditions. J. S. Afr. Inst. Min. Metall. 1991;91(1):1-7.

29. Roberts MKC. The design of stope support systems in South African gold and platinum mines, PhD thesis. University of the Witwatersrand. Johannesburg; 1999.

30. Jager AJ, Ryder JA. A handbook on rock engineering practice for tabular hard rock mines. Johannesburg: SIMRAC; 1999.

31. Daehnke A, Salamon MDG, Roberts MKC. Quantifying stable hangingwall spans between support units. J. S. Afr. Inst. Min. Metall. 2000;100:375-88.

32. Squelch AP. The determination of the influence of backfill on rockfalls in South African gold mines. M.Sc. Dissertation. University of Witwatersrand. Johannesburg; 1994.

33. Kuijpers JS, Napier JAL. The effect of loading history on stress generation due to inelastic deformations around deep-level tabular stopes. J. S. Afr. Inst. Min. Metall. 1991;91:18394.

34. Cai M, Champaigne D. The art of rock support in burst-prone ground. Keynote lecture. In: Rasim 7: Controlling Seismic Hazard and Sustainable Development in Deep Mines. Rinton Press; 2011; p. 33-46.

35. Louchnikov V, Sandy MP. Selecting an optimal ground support system for rockbursting conditions, In: Deep Mining 2017: Eight International Conference on Deep and High Stress Mining. Perth; 2017. p. 613-23.

36. Roberts D. Calibration of a numerical model for bore-and-fill mining, J. S. Afr. Inst. Min. Metall. 2017;117:705-18. 

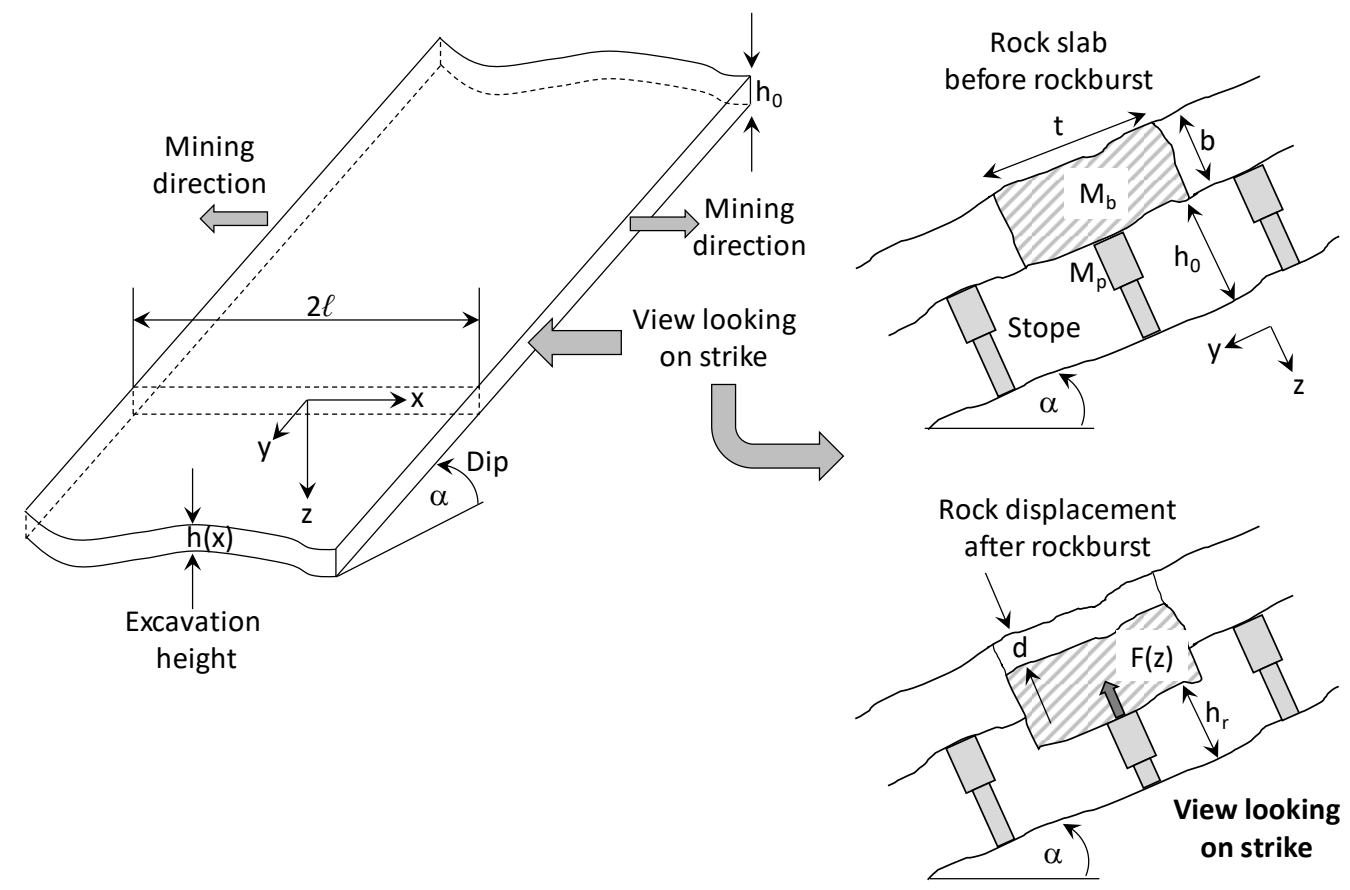

Fig. 1. Definition of terms related to a simplified support problem of a shallow dipping tabular stope. Note that the origin of the coordinate system is at the centre of the stope.

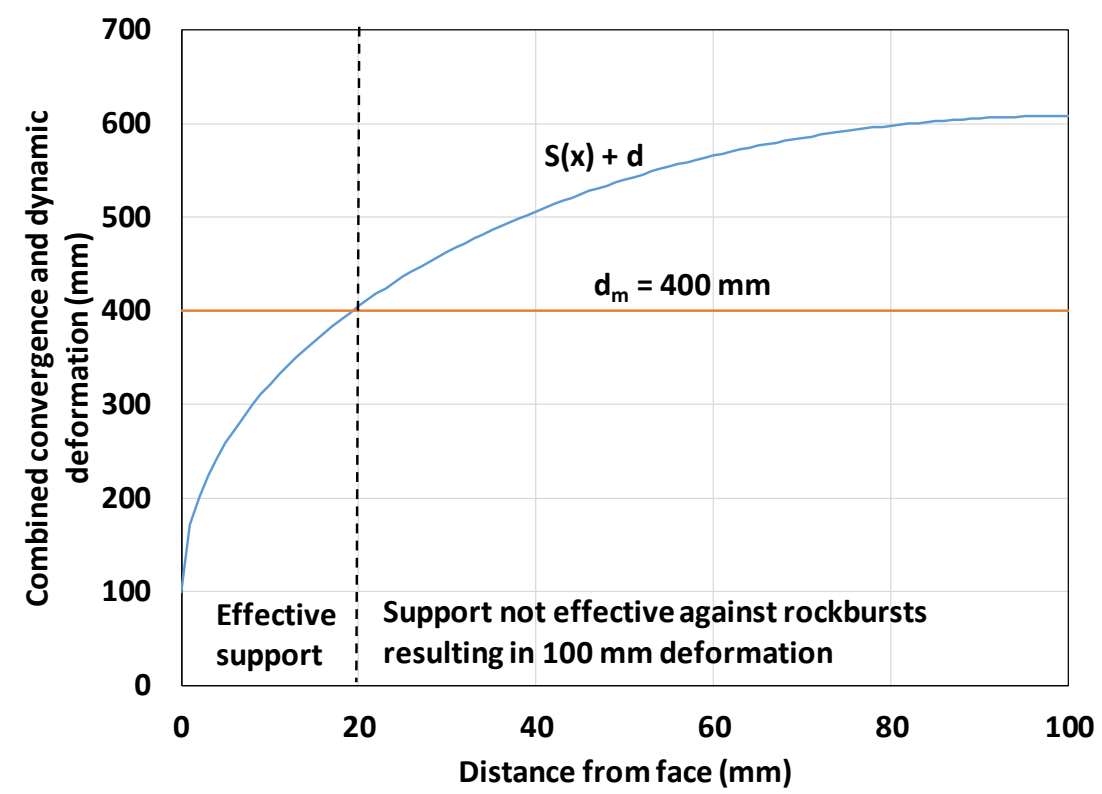

Fig. 2. An illustration of how the effectiveness of yieldable support in a tabular stope is diminished owing to the increase in convergence as the distance to face increases. For the parameters assumed, this support unit will not be effective in rockburst conditions beyond a distance of $20 \mathrm{~m}$ from the face. 


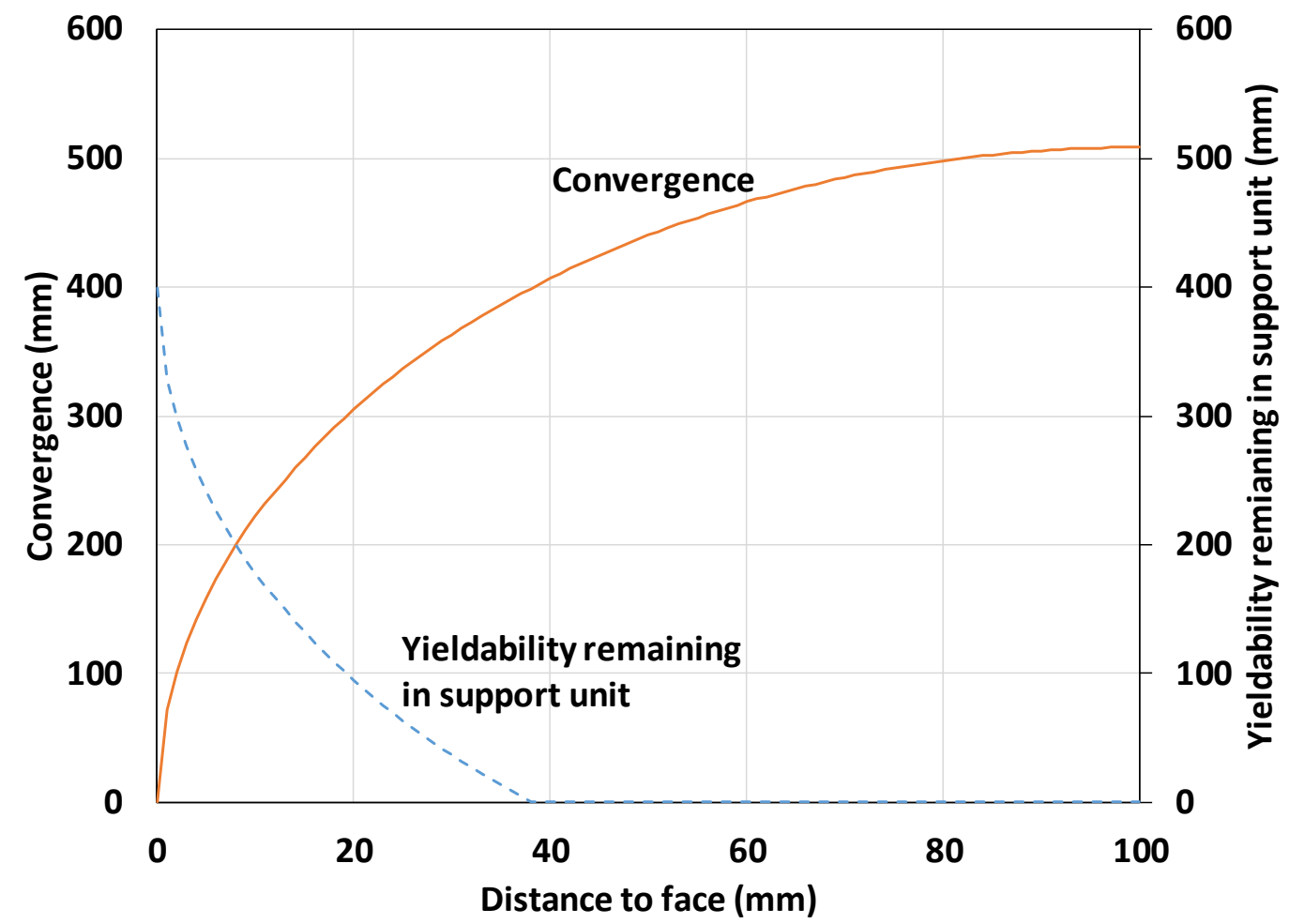

Fig. 3. Decrease in the yieldability of a support unit as it moves into the back area of a tabular stope. No rockburst occurs in this particular case. For the parameters assumed, these support units will fail at a distance of approximately $40 \mathrm{~m}$ from the face.

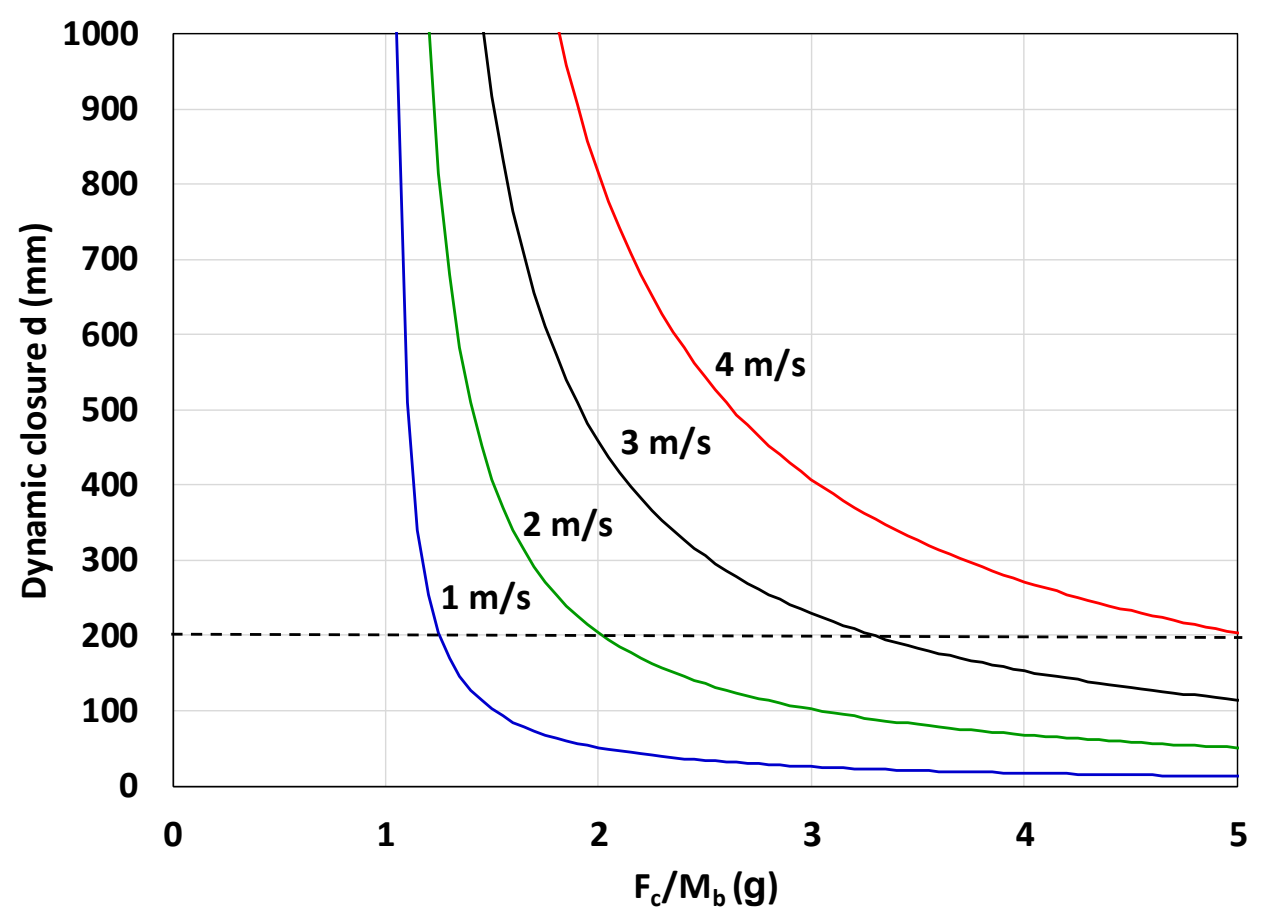

Fig. 4. Dynamic closure, $d$, plotted as a function of the ratio $\left(F_{c} / M_{b}\right)$. Note that to restrict the dynamic closure to a small value, e.g. $200 \mathrm{~mm}$, the support requirements become onerous for high ejection velocities. 


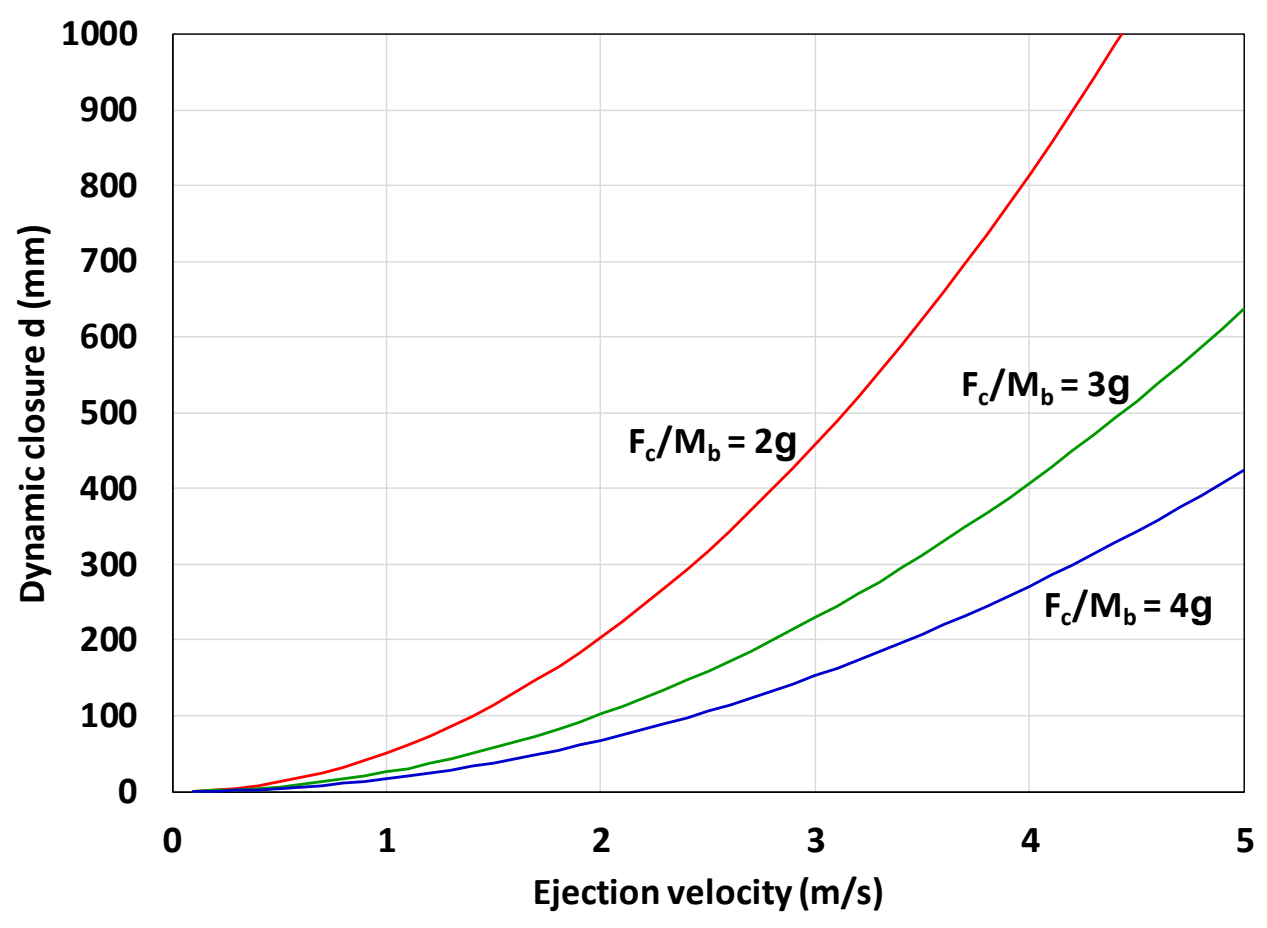

Fig. 5. Dynamic closure, d, plotted as a function of the ejection velocity. Note that at high ejection velocities, such as $3 \mathrm{~m} / \mathrm{s}$, robust support is required to restrict the closure to a small magnitude especially if the stoping width is only $1 \mathrm{~m}$.

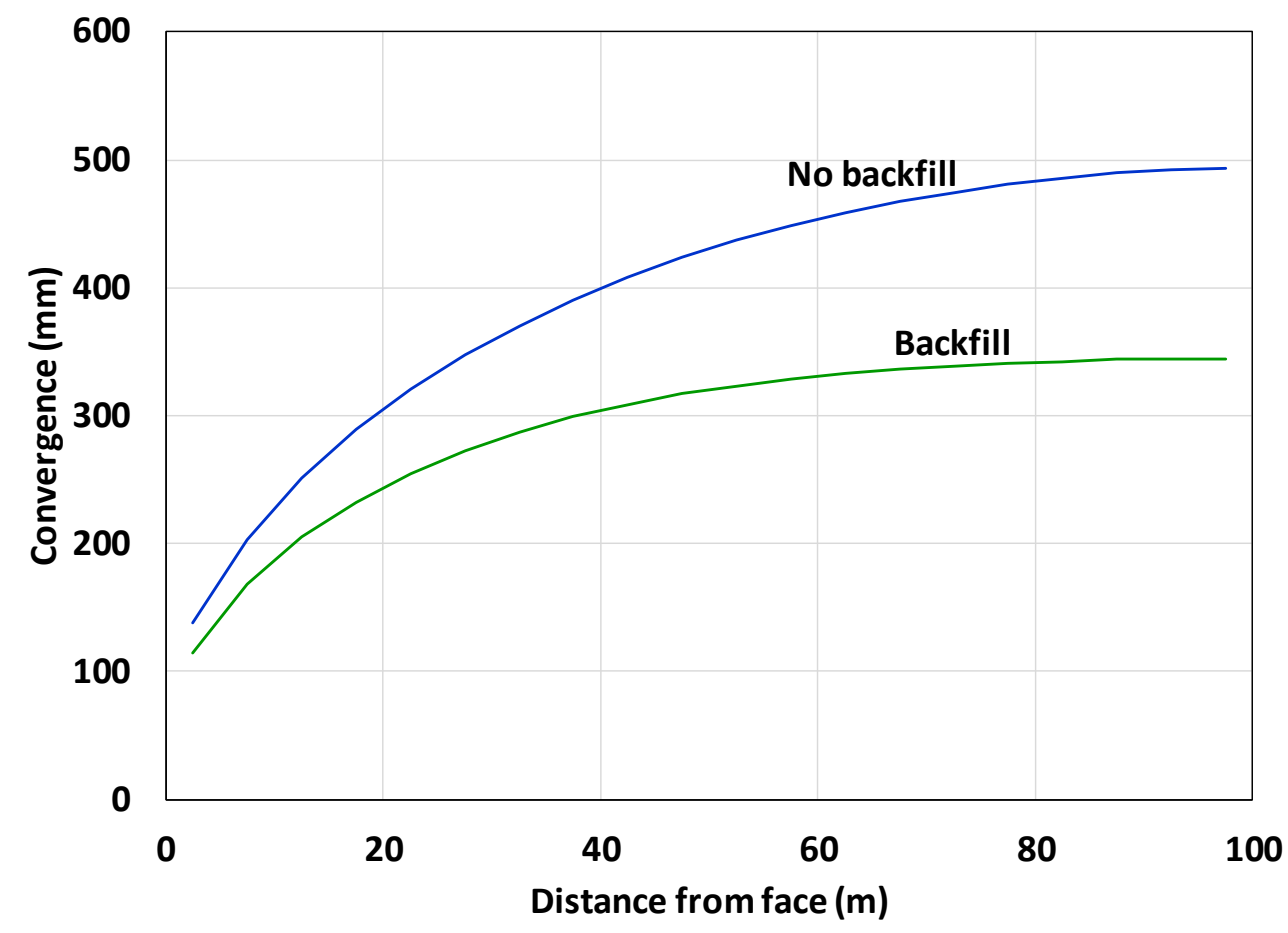

Fig. 6. The simulated effect of backfill on convergence in the stope. 

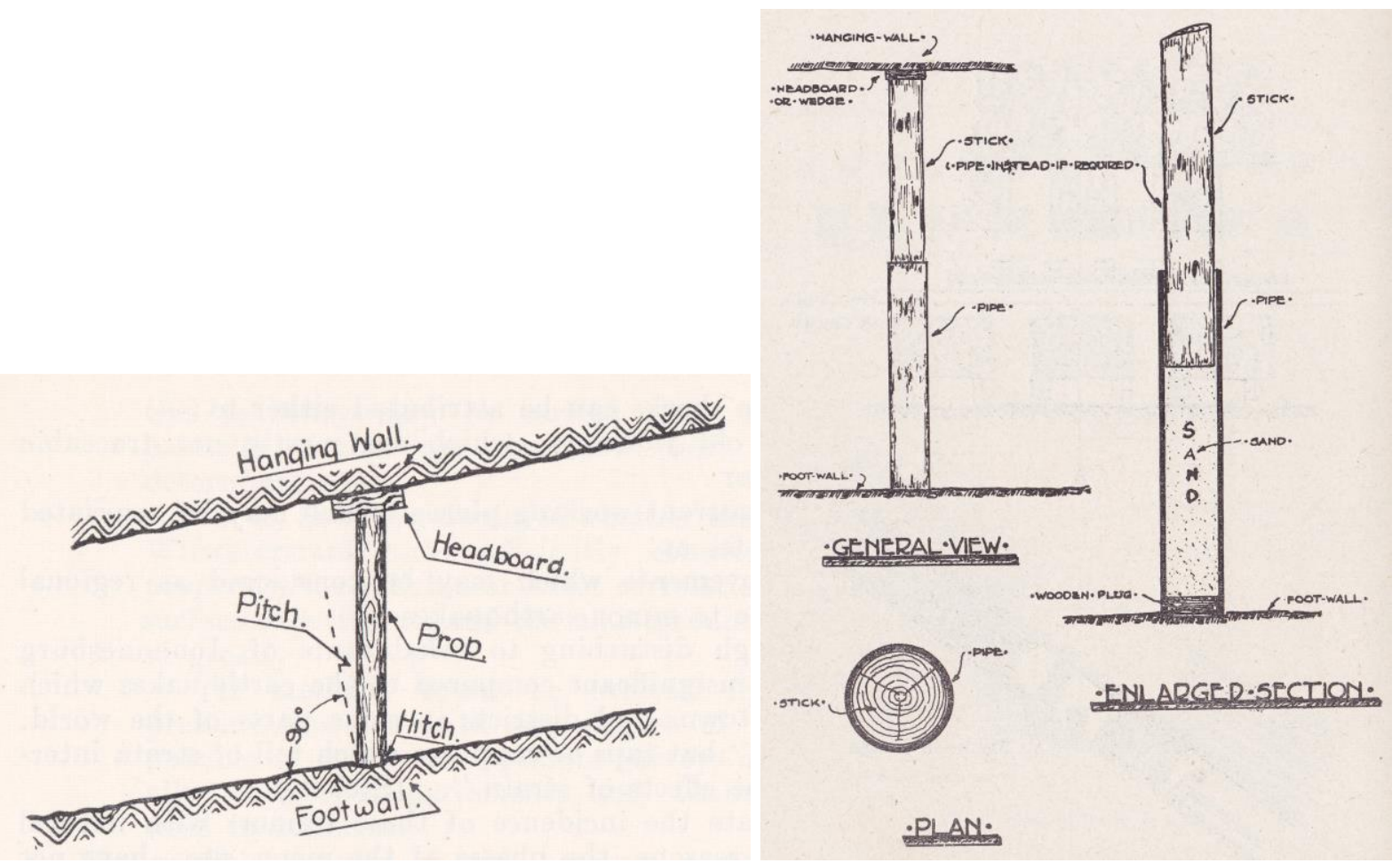

Fig. 7. a) Installation of a timber stick in a stope and b) a compressible pipe support. There was already a yielding elongate in use in the mining industry in 1946 (after Jeppe ${ }^{16}$ ).
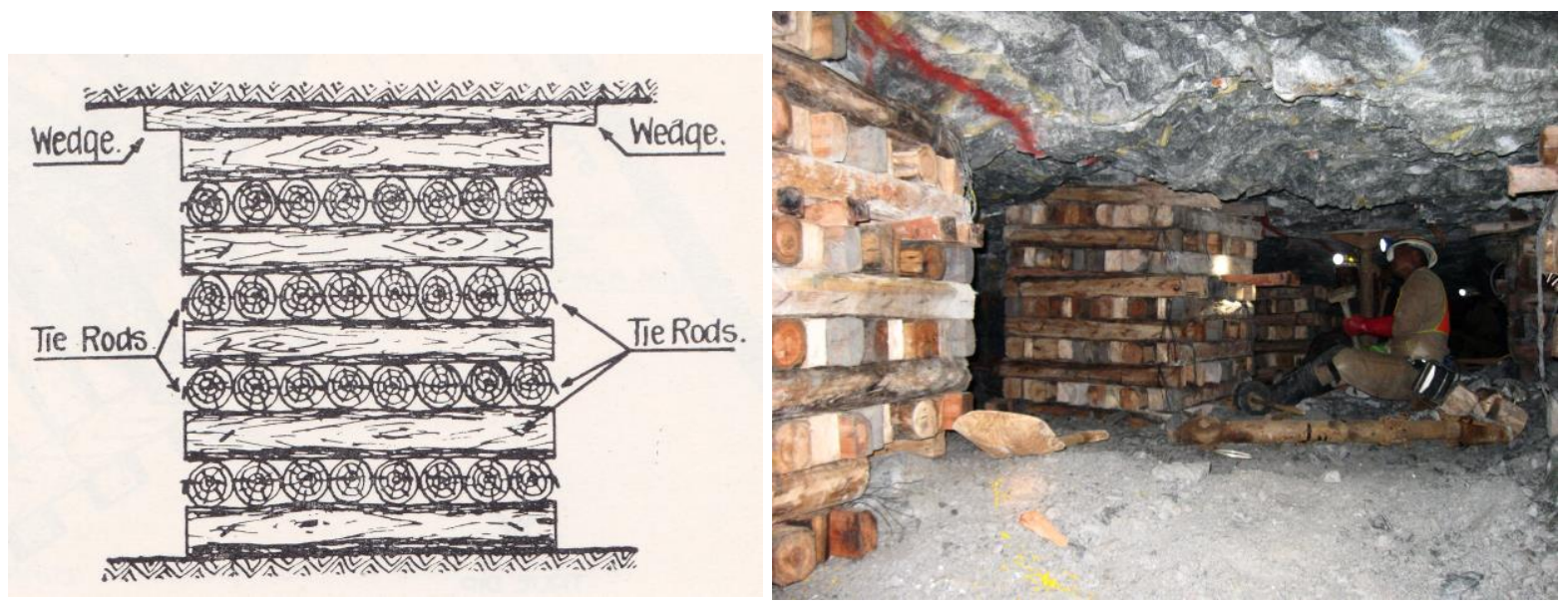

Fig. 8. a) Construction of a mat pack (left, after Jeppe ${ }^{16}$ ) and b) actual packs installed in a stope (photograph M. Grave). 


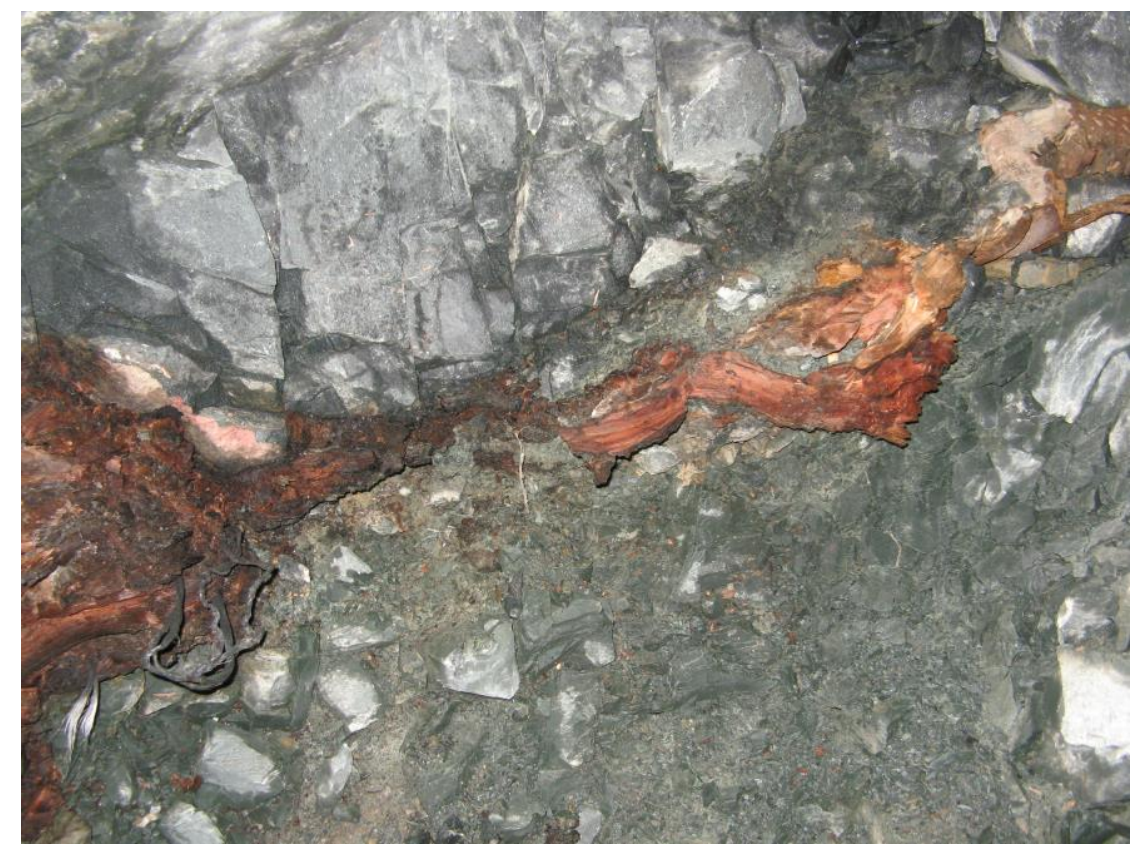

Fig. 9. Examples of total closure in the back areas of stopes where timber packs were compressed to almost nothing (photograph D.F. Malan). At this point $S(x)=h_{0}$.
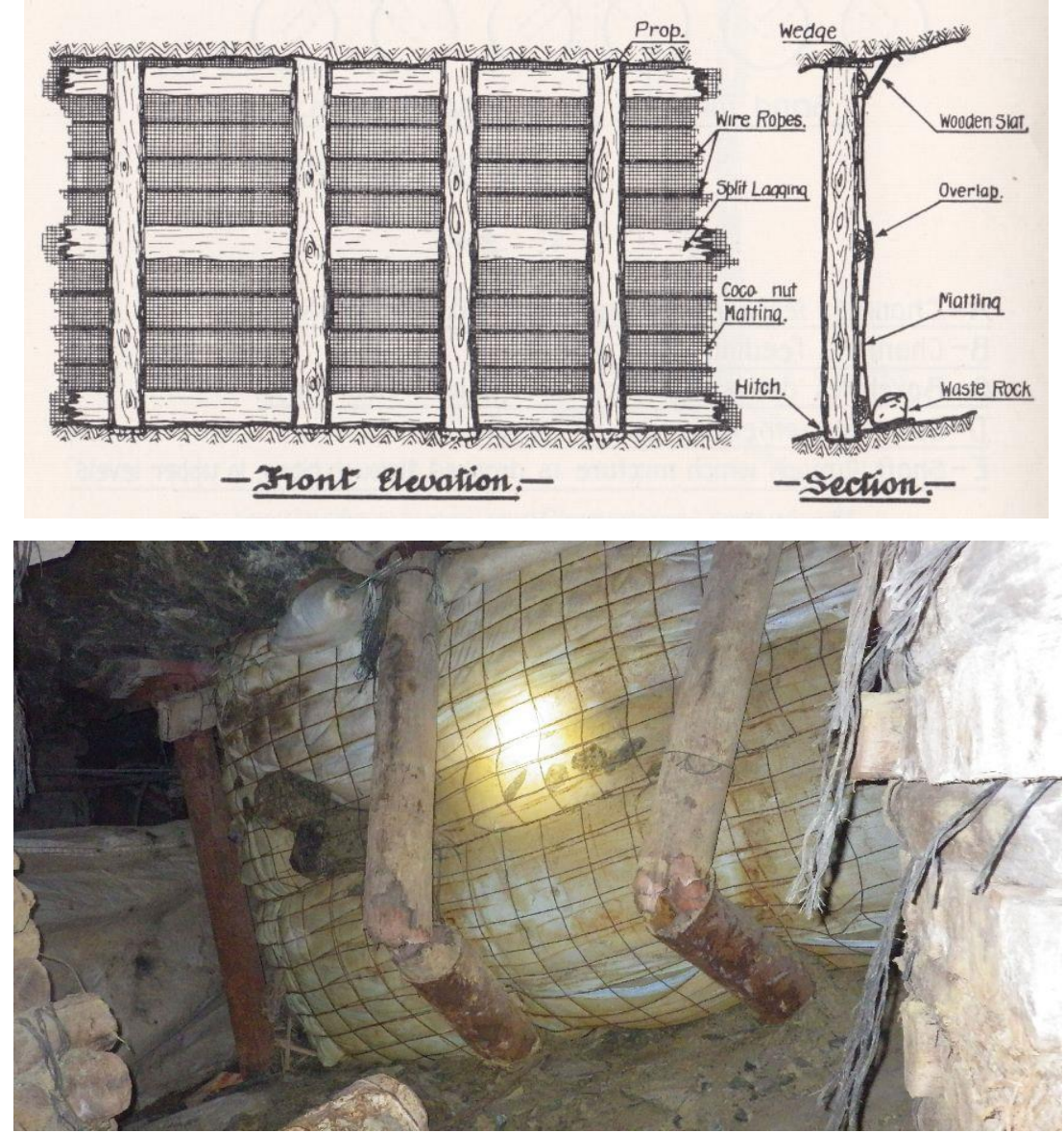

Fig. 10. a) A barricade of a sandfilling paddock as described in 1946 (after Jeppe ${ }^{16}$ ) and b) a modern filled backfill paddock. Note how the elongates buckled owing to the large amount of convergence in the back area and the bulging of the backfill bag (photograph D.F. Malan). 


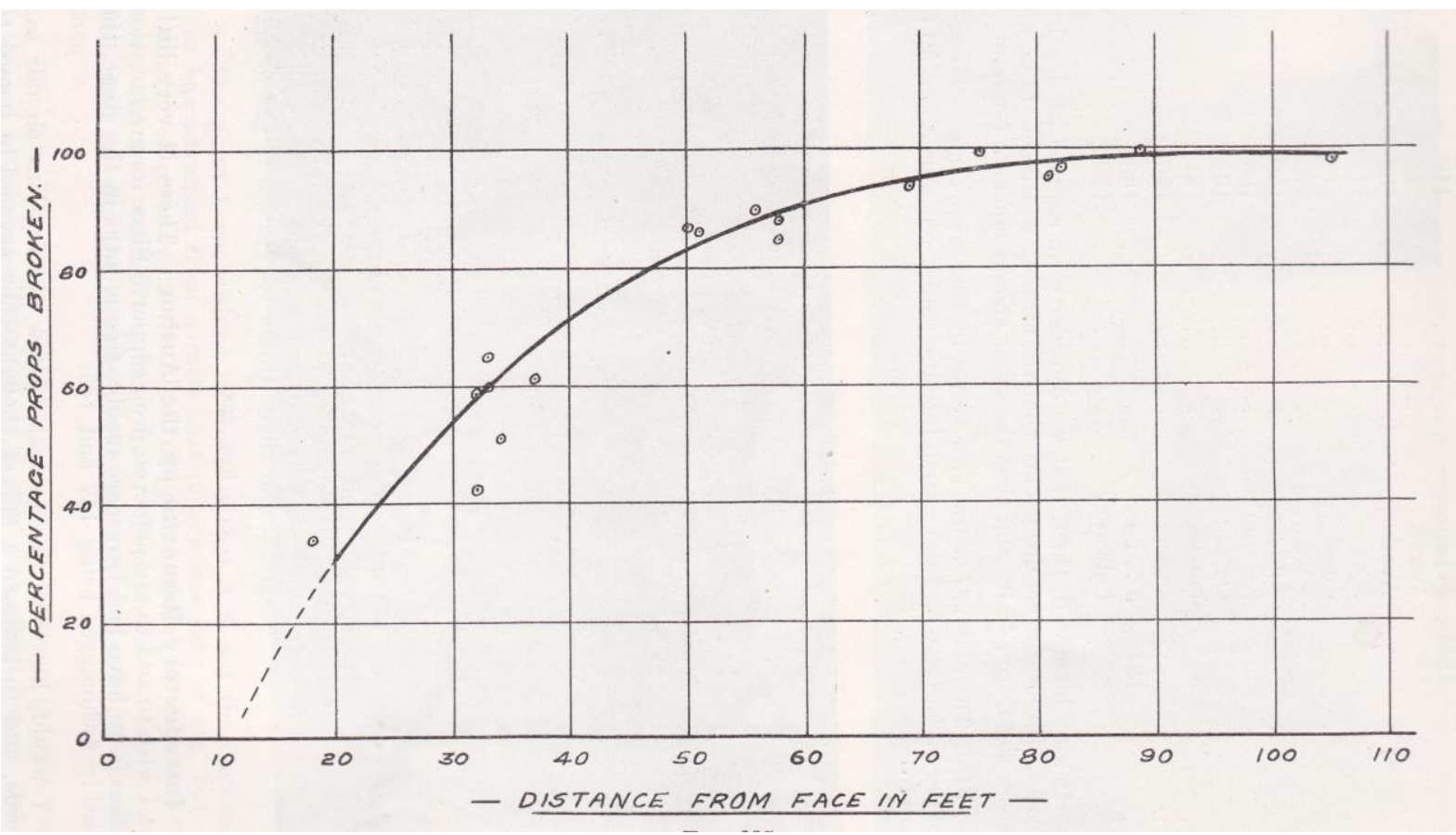

Fig. 11. Results from the experiment by Hill to use mine poles at great depth in a tabular stope (after Hill25). This illustrates the percentage of failed units as a function of distance to face.
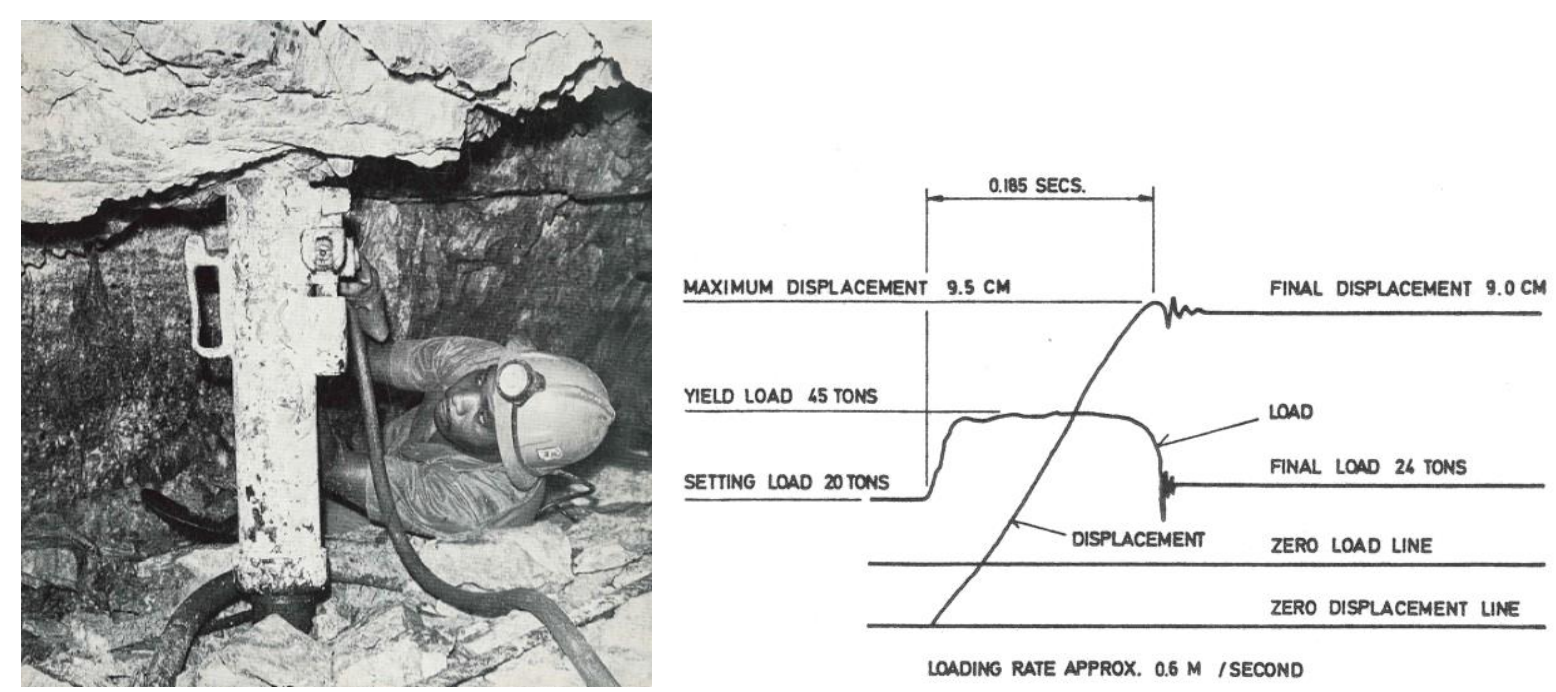

LOADING RATE APPROX. $0.6 \mathrm{M}$ /SECOND

Fig. 12. a) An early RYHP unit being installed underground (Chamber of Mines research review, 1971) and b) a graph showing the performance characteristics of these props (after Hodgson et al. $\left.{ }^{26}\right)$. 


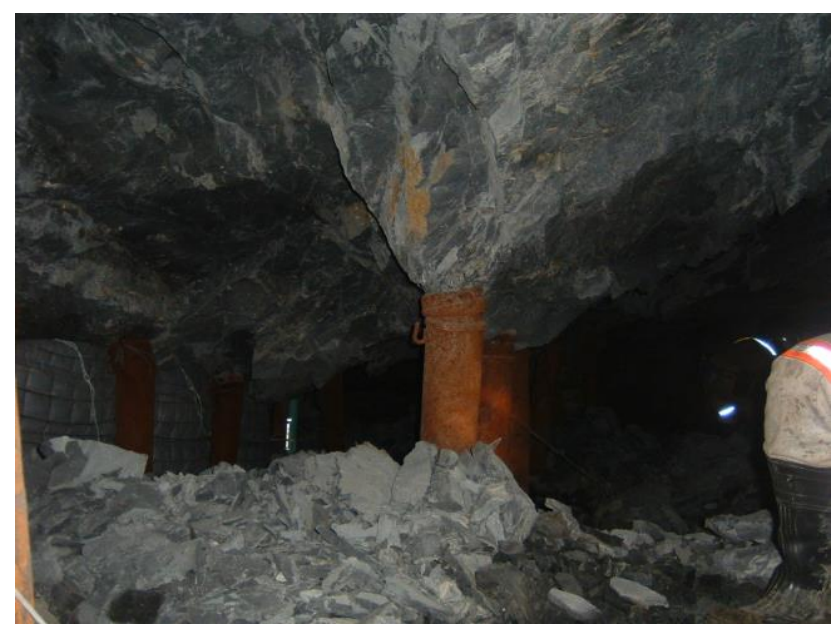

Fig. 13. A photograph illustrating the fallout between adjacent rows of elongates following a seismic event. Retaining support elements between the rows of elongates are required to prevent this fallout (photograph D.F. Malan).

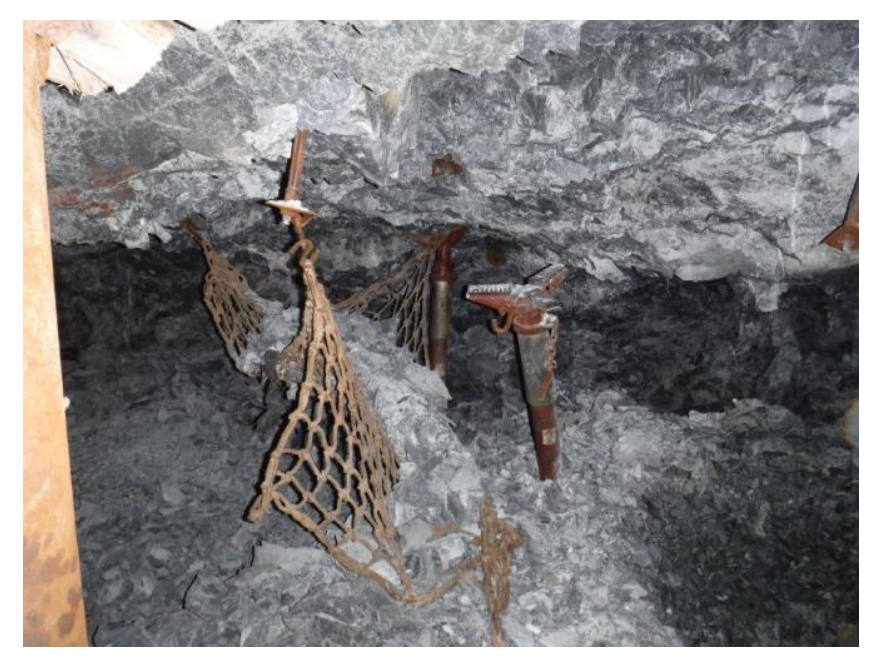

Fig. 14. Example of the failure of a weak retaining element (a removable net) during a rockburst. These nets are typically attached to the bolts and the removable steel props (photograph J.C. Esterhuyse).

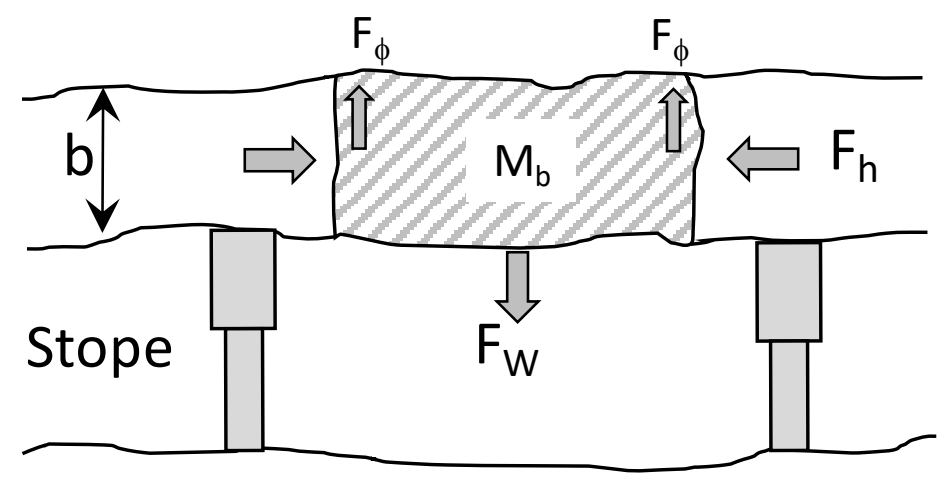

Fig. 15. A simplified problem of a quasi-stable block between two elongate support units. 